Jensen, E; Dawson, E; Falk, JH; (2011) Dialogue and Synthesis: Developing Consensus in Visitor Research Methodology. Visitor Studies, 14 (2) pp. 158-161. 10.1080/10645578.2011.608003.

Downloaded from UCL Discovery: http://discovery.ucl.ac.uk/1472914.

\title{
ARTICLE
}

\section{Dialogue and synthesis: Developing consensus in visitor research methodology}

\author{
Eric Jensen ${ }^{1}$, Emily Dawson ${ }^{2}$ and John Falk ${ }^{3}$ \\ ${ }^{1}$ University of Warwick, Coventry, UK \\ ${ }^{2}$ King's College London, London, UK \\ ${ }^{3}$ Oregon State University, Oregon, USA
}

\begin{abstract}
This brief synthesis presents the main points of agreement between Dawson and Jensen's article, 'Towards a 'contextual turn' in visitor studies: Evaluating visitor segmentation and identity-related motivations' and Falk's reply, 'Contextualizing Falk's Visitor Identity-Related Motivation Model', and highlights important considerations for future research.
\end{abstract}

The dialogue between Dawson and Jensen (this issue) and Falk (this issue) has raised a number of core theoretical and methodological issues for visitor researchers to consider. This back and forth has helped to reveal more of our underlying perspectives about visitors and the ways in which we can come to understand the contributions of institutions such as museums and zoos to the lives of both current and potential visiting publics. As readers of the two articles will know, there are still areas of disagreement. However, in this brief synthesis, we identify some of the main points on which we agree at the end of our dialogue in order to highlight directions for future visitor research.

Both articles raise the need to engage with theory when conducting visitor studies. While not agreed on precisely which theories might be of most use, we are agreed that drawing more widely on theory, including theories about identity, learning and culture, enriches research about the relationships between people and cultural institutions. As Falk points out, "lacking still are fundamental models and theories" (p.20, this issue), for the field of visitor studies. As such, it is through theoretical interventions like Falk's model of visitor-identities and critical discussions about it, that theoretical advances in visitor studies can beforged. One key theoretical implication of this dialogue is a broader focus on how cultural institutions fit into people's lives (or not).

Indeed, we share a deep interest in the "long-term meaning making of museum visitors" (Falk, this issue). The "contextual turn" alluded to by Dawson and Jensen (this issue) shares with Falk's visitor-identity model a commitment to framing people's experiences of cultural institutions in terms of their broader lives. The contextual turn therefore widens "our understanding of the context of museum visits and concomitantly shift[s] how visitors are conceptualized" ( $p$. X, Dawson and Jensen, this issue). While we all acknowledge the practicality of restricting investigations of visitors to the temporal and physical boundaries of the museum, a growing body of research suggests that this perspective limits what we can ultimately understand (cf., Anderson, Storksdieck \& Spock, 2007; Falk, 2004). We would argue that whenever possible investigators should employ a broader perspective whichencompassesthe experiences of visitors (and those who do not visit) beyond the museum walls. 
We are firmly agreed on the point that what "visitors find important in these venues is most frequently tied to visitors' needs and agendas, rather than to the institution's needs and agendas. Thus, memories and meanings only partially coincide with the "learning outcomes" espoused by most museums" (Falk, this issue). Jensen (2011b) goes further and reports on evidence that retrograde or negative learning can and does also happen during visits that are ineffectively guided. Moreover, Dawson(2011b)has argued that museum experiences can be off-putting, resulting in people believing that cultural institutions are not for them(also see Jensen, 2010).

It is particularly important, therefore, to understand the "underlying reasons why people do, and do not see value in a visit to a museum"(Falk, this issue). As Falk (this issue) highlights, these are "reasons that often have only an indirect relationship to the actual content and traditionally assumed value of museums". Rather visitors have a complex array of interests, desires and needs, only some of which can be addressed for some people through the existing structure and approaches of museums, galleries and other cultural institutions. Indeed, we agree that there needs to be a shift in favour of visitors' interests and needs on the part of cultural institutions. Though there may be practical limitations, we are agreed that a full explanation of current and potential visitors' interests and needs would be best achieved through an"inclusive approach that incorporates motivations, identities and sociological variables such as class and ethnicity" (Dawson \& Jensen, this issue).

Through both articles an interest in not leaving 'non-visitors' behind within the field of visitor research emerges.As Falk argues, "Just as some people possess a knowledge of the "benefits" that museums afford, it is equally important to appreciate that there are also large numbers of people who don't perceive that museums possess these affordances" ( $p . x$, this issue). Indeed, as Dawson's research has found, not only may some people not perceive such affordances, structured inequalities can, in some cases, literally prevent people from accessing such "benefits"(Dawson, 2011a). We are agreed, therefore, on the dangers of restricting 'visitor' studies only to current visitors. While existing visitors are undoubtedly of interest to this field of research, there is a clear and pressing need to expand this focus, not only in terms of people's lives and experiences, but in terms of 'who' we work with. Falk and Needham (2011) can be seen as one recent example of this effort to widen the lens of visitor research by starting from an investigation of the entire local community and working back to visitor impacts.

In addition to widening the lens of visitor studies, we are committed to identifying ways in which practice can be improved for the benefit of visitors to cultural institutions such as museums and zoos. Indeed, as Falk (2009) said, good engagement practice "requires understanding not just the needs and wants of the public, but how those needs and wants can best be served by the resources and capabilities of the museum. The most successful museums are those who have found ways to merge their own interests and capabilities with those of their publics"(p. 239). This point highlights that the visit experience is a negotiation between visitors' perspectives and institutional perspectives. It is vital that practitioners learn to strike that balance effectively. Such a relationship between visitor studies research and museum practice is undoubtedly a key part of visitor studies, alongside broader goals about exploring the relationships between people and cultural institutions. As Dawson and Jensen suggest, including "visitors' interests and motivations based on factors outside of the cultural institutions is likely to be more fruitful in developing an accurate understanding of such institutions' impacts" (p. X, this issue).

Finally, discussions like these raise important issues for methodological transparency, quality and rigour(e.g. see Jensen, 2011a; Jensen \& Holliman, 2009). In terms of overall research approaches, we are agreed that a mixed methods approach is often most appropriate in order to mitigate the inherent limitations of any one particular method. A mixed methods approach can be particularly valuable when one begins to grapple with the complex 
and challenging task of rigorously evaluating long-term visitor impacts and related issues. Such a task is not for the faint of heart or the methodologically ill-equipped. Advanced qualitative and quantitative research methods, as well as integrated designs are essential tools in this domain.

To unlock the full potential of visitor studies, progress is needed at a theoretical level in order to develop models of publics and visitors that can sustain research of ever greater quality and complexity. Greater accuracy and explanatory power in visitor research also offers benefits for cultural institutions that draw on this research to inform their interventions aimed at promoting positive social change in contemporary societies (Jensen \& Wagoner, 2009). We hope some progress has been made in this important endeavour with our interventions in the field, but we invite the participation of others in engaging with the big questions that will define this field of research and practice for years to come.

\section{References}

Anderson, D., Storksdieck, M., \& Spock, M. (2007).Understanding the long-term impacts of museum experiences. In J. Falk, H., L. Dierking, D., \& S. Foutz (Eds.), In principle, in practice: Museums as learning institutions (pp. 197-215). AltaMira Press.

Dawson, E. (2011a). Science and the exclusive society: A study of four minority ethnic communities and their engagement with public science. Unpublished thesis. King's College London, London.

Dawson, E. (2011b). Whose museum? Museum, American Association of Museums, July/August.

Falk, J.H. (2004). The director's cut:Towards an improved understanding of learning from museums. Science Education, 88, S83-S96.

Falk, J.H. (2009). Identity and the museum visitor experience. Walnut Creek, CA: LeftCoast Press.

Falk, J.H. \& Needham, M. (2011).Measuring the impact of a science center on its community. Journal of Research in Science Teaching, 48(1), 1-12.

Jensen, E. (2010). Something Different: A pilot study evaluating family outreach activities at the Fitzwilliam Museum. Retrieved from http://research.mla.gov.uk/evidence/documents/something-different-fitzwilliam2010.pdf

Jensen, E. (2011a). Evaluate impact of communication. Nature, 469, 162.

Jensen, E. (2011b). Learning about animals, science and conservation: Large-scale surveybased evaluation of the educational impact of the ZSL London Zoo Formal Learning programme. London: University of Warwick.

Jensen, E., \& Holliman, R. (2009). Investigating science communication to inform science outreach and public engagement. In R. Holliman, E. Whitelegg, E. Scanlon, S. Smidt \& J. Thomas (Eds.), Investigating science communication in the information age: Implications for public engagement and popular media (pp. 55-71). Oxford: Oxford University Press.

Jensen, E., \& Wagoner, B. (2009). A cyclical model of social change. Culture \& Psychology, 15(2), 217-228. 